\title{
Charles Atlas. Edited by Lauren Wittels. Contributions by Charles Atlas, with the assistance of Johanna Fateman, Stuart Comer, Douglas Crimp, Douglas Dunn, Lia Gangitano. 2015. Munich, New York: Prestel, 303 pp, chiefly color screen stills. \$75 hardcover. ISBN: 9783791381008
}

Kyle Bukhari, Sarah Lawrence College

Keywords: Charles Atlas, Merce Cunningham, postmodern dance, screendance, video art

Throughout his career as a filmmaker and visual artist, Charles Atlas' work has expanded the boundaries of film and video, with projects and collaborations that have spanned concert dance, performance and visual art, music, and underground club and drag subculture. In doing so, Atlas has moved across genres, techniques, and styles, forging an aesthetic approach that is uniquely his own. As the recent monograph from Prestel, titled Charles Atlas (2015), ${ }^{1}$ makes clear, Atlas is a central, if not the central, figure in the development of what is known today as the distinct genre of screendance, choreography conceived within the technical parameters of film and video. ${ }^{2}$ Yet who would have known that when he collaborated with Merce Cunningham on the groundbreaking dance film Channels/Inserts (1981), ${ }^{3}$ Atlas' original inspiration was the wedding scene in Francis Ford Coppola's The Godfather (1972)? ${ }^{4}$ Or, that when Atlas was approached by UK's Channel 4 to make the arts documentary that became Hail the New Puritan (1987), he proposed to showcase the then relatively unknown twenty-one-yearold Michael Clark whom Atlas had met while working with Karole Armitage during her "punk ballet" period of the early 1908s? ${ }^{5}$ This new volume combines just such anecdotal revelations by the artist and his collaborators in tandem with a richly visual selection of color and black-and-white screen stills drawn from his archive. Along with the scholarly, art historical essays and interviews, the overall effect is robustly multivocal, providing the reader with a valuable and nuanced perspective on Atlas' work that not only encapsulates the artist's often surprising intentions, but also the historical significance and critical reception of his expansive artistic oeuvre.

With the assistance of writer and musician Johanna Fateman who helped turn Atlas' thoughts and memories into a continuous narrative presence within the book, the reader is led through his works for film and video from 1970 to 2014 . What ensues is both a comprehensive and personal look into his archive that encompasses his carefully cultivated collaborations with some of the key innovators in dance postmodernism on The International Journal of Screendance 10 (2019).

https://doi.org/10.18061/ijsd.v10i0.6824

(c) 2019 Bukhari. This article is published under a Creative Commons Attribution 4.0 International License (https://creativecommons.org/licenses/by/4.0/) 
both sides of the Atlantic, including Cunningham, Clark, Karole Armitage, Yvonne Rainer, Douglas Dunn, and Phillipe Decoufflé, as well as performance artists such as Leigh Bowery, Marina Abramovic, DANCENOISE, Mika Tajima/New Humans, and the singer ANOHNI.

The major portion of the book is dedicated to Atlas' film and videography and is divided into seven thematic and chronologically structured chapters. They contain the author's earliest work (1970-1974), most notably with Dunn; his initial collaborations with Cunningham (1975-1983); documentary works (1983-2012) that feature artists such as Armitage, Decoufflé, Clark, Abramovic, and Bowery; live video/multimedia performance works (2003-2013) that showcase his work with Tajima/New Humans among others; and, video shorts, collages, featurettes (1990-2010) that include a cast of wickedly brilliant New York downtown performance artists such as Richard Move, John Kelly, Joey Arias, and Lucy Sexton and Anne lobst of DANCENOISE. These temporally overlapping yet distinct chapters include works such as his film of Cunningham's Walkaround Time (1972) and Torse (1977), his collaboration with Clark for Hail the New Puritan (1986), the live video portrait project Instant Fame! (2003/2006) that took place in the galleries of Participant Inc. in New York and Vilma Gold in London, and the historical and witty "featurette" on postmodern dance, titled Rainer Variations (2002), consisting of reedited material from Rainer's personal film archive. More recent video installations are also represented. Those include the haunting The Hanged One (1997, the Whitney Museum), Martha, Martha, Martha (2000) culled from what Atlas screened at the New York underground nightclub Martha@Mother's, hosted by performance artist and Martha Graham impersonator Move. Also included are his most recent, highly abstracted numerically based works for video-Plato's Alley (2008) and 143652 (2012). Atlas' survey ends with his late Cunningham collaborations (2000-2010), when the two artists reunited in 2000 to film a documentary of the choreographer Merce Cunningham: $A$ Lifetime of Dance (2000), and to create several films that document the iconic choreographer's last phase of production such as Melange (2000), Biped (2000/2005) and their final work together completed after Cunningham's death, Ocean (2010).

Across the chapters, fascinating historical details and new insights abound. For instance, in chapter seven: Cunningham Collaborations and Documents, we learn that in 2010, Atlas discovered his lost $16 \mathrm{~mm}$ footage of Exchange (1978) that had been mislabeled and stored in an off-site archive by the Cunningham company after Atlas' departure in 1983. Upon rediscovery, Atlas transferred the footage to high-definition video with sound and released it in 2013 under the video art label Electronic Arts Intermix. As Atlasthe narrator reveals, the work is important, as it captures Merce at age sixty, dancing his own choreography at full capacity with his company, dressed in the pollution-inspired "sooty grey" costumes designed by collaborator Jasper Johns. ${ }^{6}$

As the book clearly reveals, Atlas' work in the technological medium spans both analog and digital production, and the overview in the monograph allows the reader to make 
insights into the development of the screendance form. We can track Atlas' relationship to technology from his early use of Super $8 \mathrm{~mm}$ film in the 1970 s, to the early video system used to capture Cunningham dancing in the iconic Blue Studio: Five Segments (1976). Seeing the incorporation of live video monitors on the stage in Cunningham's Fractions 1 (1978), the reader witnesses a vanguard experiment that combined simultaneous live and broadcast action. The introduction of the Steadicam into the actual choreography with Locale (1980), as well as the use of a moving-crane camera in Coast Zone (1983) created entirely new ways of thinking about the space of the spectator. In a remarkable creative full circle-through the use of digital technologies in live performance in the 2000s-with works like Dunn's Muscle Shoals (2003) and more recent performances at The Tanks at the Tate Modern (2013), Atlas reveals that he had taken up John Cage's chance procedures, something he had rejected when he worked with the composer many years earlier. ${ }^{7}$

The book is highly visual, with each of the sections replete with multiple still images alongside textual, often-humorous and insightful recollections and musings on the production and editing process. In some cases, Atlas' stills reveal the progression of a single image, as in his collaborations with Dunn in the color-saturated, Édouard Manetinspired Mayonnaise Number One (1973), or the more minimal and formal black and white film Floor (1974/2010). ${ }^{8}$ In other instances, such as in the film of Cunningham's Torse (1977), Atlas presents close-ups and more distant shots of the same moments of the dance in a split-screen, showing the flesh-colored, unitard-clad dancers as if floating against a black, two-dimensional background. On those pages, the idea of choreography in the abstract is brought into stark relief within the video diptych. ${ }^{9}$ Ultimately, the relationship between the image and the text throughout the book creates a perspectival parallax on the individual works themselves that adds both depth and nuance to their contemplation. This dialogue between media enhances and enriches the aesthetic discourse on the visual medium of film and video in relation to dance, working together in a way that prioritizes the optics of Atlas' work while punctuating it with delightful and irreverent textual insights.

In addition to Atlas' voice, the monograph includes several text by other authors, selected by the editor Lauren Wittels, of Luhring Augustine Gallery in New York. These include essays by art historian Douglas Crimp, and Lia Gangitano (founder of the New York Lower East Side Gallery known as Participant Inc.), and two interviews with Stuart Comer (curator of Media and Performance at the Museum of Modern Art in New York), as well as with Atlas' long-time collaborator Douglas Dunn. Each of these voices adds depth and perspective to the reader's understanding of Atlas' work. In particular, Crimp's substantial essay on Atlas' early films for Cunningham provides an art historical context within which to consider this prolific collaboration, and Cunningham's lasting influence on Atlas, as well as Atlas' impact on the choreographer and the legacy of Atlas' films and video of Cunningham's oeuvre. For Crimp, Atlas provided Cunningham not 
only with the new two-dimensional realm of film and video as a platform for choreographic experimentation, but also with the possibility to visually realize a dynamic method of framing the dance that mirrored the unpredictable movement of the human eye as it views Cunningham's non-hierarchical and spatially decentralized choreography. Crimp's detailed and technical discussion of the ways in which Atlas' integration of the Steadicam in Cunningham's Locale (1980) makes explicit how Atlas' choreographed movements for the camera inserted directly into the dance were a key innovation in both the technical development of dance film and video, and the way that the effect of being inside of the choreographic action offered a new way of looking at dance.

Comer's two interviews with Atlas, the first reprinted from frieze magazine (2011), the second (2014) conducted especially for this book, provide further biographical and sociocultural background for the reader. ${ }^{10}$ The discussion of Atlas' early cinematic influences of D.W. Griffith, Stan Brakhage, and Andy Warhol, alongside references to other influential films and directors reiterate the influence of both popular and experimental cinema on the artist's work. To understand Atlas' aesthetic is also to grasp the social aspect of his work, his artistic milieu and taste for the subcultural in New York and London, and Comer brings this to the foreground, prompting Atlas to confess that in the 1980s "London was so much more fun than New York". ${ }^{11}$ Atlas also speaks to Comer about the role his own homosexuality has played in his aesthetic choices, and how his films expose a variety of possible sexual identities that exist outside the realm of the heteronormative. In their second interview, the lesser known subject of Atlas' work as a lighting and costume designer comes up, as well as the artist's somewhat reluctant move into the blue-chip art world of museums and galleries. We also learn that this reconsideration of his artistic value systems coincides with Atlas' recent video works, including Painting by Numbers (2011) and Plato's Alley (2012). These are works that could be described as purely numerical abstractions, and are the product of Atlas imagining himself to be a completely different artist from what he has been up to that point. Speaking of his recent large scale shows with multiple screens distributed throughout the exhibition spaces, Atlas discusses his evolving practice of choreographing the performance space itself, where the spectators travel through what he describes as "the fixed moving images," an experience not far from the memories of the "haunted-house rides" at the amusement park from his childhood. ${ }^{12}$ In the interviews with Comer, we learn about Atlas' look into the future of his work, as well as about his present-day concerns with artistic contexts and economies, revealing the profound influence that choreographic thinking, and his work with so many different choreographers, has imprinted on Atlas himself.

This splendid book will hold interest for a broad readership including but not limited to those who work within the fields of dance, performance and visual art. Similarly, it is essential reading for cultural historians of late twentieth and early twenty-first century 
subcultures as expressed through technologically mediated artistic spaces, and is indispensable reading for scholars and researchers interested in the technological and aesthetic development of dance for film and video. As the book was published in 2015, it predates Atlas' more recent collaboration Tesserract (2017), ${ }^{13}$ a spectacular 3-D dance film and performance made with former Cunningham dancers Rashaun Mitchell and Silas Riener. With all the existing rich insights in this book, a final essay to round up the plethora of ideas offered might be helpful to the reader, although a more recent book, also entitled Charles Atlas (2019), seems to address this discursive gap. ${ }^{14}$ Nevertheless, the value of the book is the many voices it contains, all of whom paint a multidimensional portrait of the artist, each in their own words. Prestel's Charles Atlas is a plentiful resource to explore the artist's trajectory and oeuvre, to learn more about his collaborative process and about the innovations that his encounters with dance and choreography sparked for his use of the camera, film, and video technology. The constellation of strikingly vivid still images in the book veer from the formally choreographic to the gender fluid, the surreal and high camp, the violent and the absurd, and taken together enthuse the reader to better understand Atlas' integral role in the history and development of screendance and its engagement with the broader social and artistic discourses from the late twentieth century up until today.

\section{Biography}

Kyle Bukhari studied Anthropology and Philosophy of Art at Columbia University, and Dance Studies at the University of Roehampton, London where he was a 2013-14 USUK Fulbright Fellow in Dance. He has danced with the Joffrey Ballet, New York, and the Zurich Ballet, Switzerland and was a winner of the Best German Dance Solo (1998). In 2013 Kyle performed at the Whitney Museum, New York with anthropologist Michael Taussig and currently collaborates with New York choreographers Jodi Melnick and Yanira Castro. Kyle is on the faculty at Sarah Lawrence College, New York where he supervises the written MFA thesis module.

Email: kbukhari@sarahlawrence.edu

\section{Notes}

${ }^{1}$ Lauren Wittels, Charles Atlas. 
2 Douglas Rosenberg, "Introduction", 1-2.

${ }^{3}$ Charles Atlas, Merce Cunningham, and David Tudor. Channels/Inserts.

${ }^{4}$ Francis Ford Coppola and Mario Puzo. The Godfather.

${ }^{5}$ Charles Atlas and Johanna Fateman, 64.

${ }^{6}$ Idem., 256.

${ }^{7}$ Charles Atlas in Conversation with Stuart Comer, 271.

${ }^{8}$ Wittels, 14-19.

${ }^{9}$ Idem., 30-31.

${ }^{10}$ Charles Atlas in Conversation with Stuart Comer, 264-71, 272-79.

${ }^{11}$ Idem., 270.

${ }^{12}$ Idem., 276.

${ }^{13}$ Charles Atlas, Rashaun Mitchell, Silas Riener Tesseract, Walker Art Center (2017).

${ }^{14}$ Raphael Gygax. (Ed.) Charles Atlas.

\section{References}

Channels/Inserts Dirs. Charles Atlas, Merce Cunningham and David Tudor. 1981. Film. https://dancecapsules.mercecunningham.org/overview.cfm?capid=46038.

The Godfather. Dirs. Francis Ford Coppola and Mario Puzo. 1972. Los Angeles:

Paramount Pictures.

Gygax, Raphael (Ed.) Charles Atlas. Zurich: JRP Ringier, 2019.

Rosenberg, Douglas. "Introduction." The Oxford Handbook of Screendance Studies. New York: Oxford University Press, 2016, 1-2. https://doi.org/10.1093/oxfordhb/9780199981601.001.0001

Tesserract. Rashaun Mitchell, Silas Riener, and Charles Atlas. 2017. Minneapolis: Walker Art Center.

Wittels, Lauren (Ed.) Charles Atlas. Munich/New York: Prestel, 2015. 